\title{
Polycyclic Aromatic Hydrocarbons from Asphalt Binder: Extraction and Characterization
}

\author{
Lucidalva S. Pinheiro, ${ }^{*, a}$ Paulo R. N. Fernandes, ${ }^{b}$ Rivelino M. Cavalcante, ${ }^{b, c}{ }^{,}$Ronaldo F. Nascimento, ${ }^{c}$ \\ Jorge B. Soares, ${ }^{d}$ Sandra A. Soares ${ }^{b}$ and José A. K. Freire ${ }^{\dagger, a}$ \\ ${ }^{a}$ Departamento de Física, Universidade Federal do Ceará, Campus do Pici, CP 6030, 60455-900 Fortaleza-CE, Brazil \\ ${ }^{b}$ Departamento de Química Orgânica e Inorgânica, Universidade Federal do Ceará, Campus do Pici, \\ CP 12200, 60455-760 Fortaleza-CE, Brazil
}

'Departamento de Química Analítica e Físico Química, Universidade Federal do Ceará, Bloco 940, Campus do Pici, 60451-970 Fortaleza-CE, Brazil

${ }^{d}$ Departamento de Engenharia de Transportes, Universidade Federal do Ceará, Campus do Pici, CP 6001, 60455-760 Fortaleza-CE, Brazil

\begin{abstract}
O ligante asfáltico de petróleo é comumente empregado na pavimentação de ruas e estradas de rodagem. Esse material contém hidrocarbonetos policíclicos aromáticos (HPAs) e diversos outros componentes alifáticos e aromáticos. Os HPAs são compostos poluentes que podem induzir problemas de saúde. Este trabalho tem como objetivo extrair e caracterizar os HPAs presentes no ligante asfáltico e suas concentrações. Dispersão de Matriz em Fase Sólida foi utilizada como técnica para a extração dos HPAs. Para análise e caracterização foram utilizadas as técnicas de Cromatografia Gasosa e Microscopia de Tunelamento. Quinze dos HPAs prioritários listados pela USEPA (United States Environmental Protection Agency) e também coroneno foram encontrados nas amostras analisadas.
\end{abstract}

The asphalt binder, derived from petroleum, commonly employed in road paving contains PAHs (Polycyclic Aromatic Hydrocarbons) and a variety of other aliphatic and aromatic compounds. PAHs are pollutants that can induce health problems. This work aims to extract and characterize the PAHs in samples of asphalt binder and its concentration. Matrix solid phase dispersion was used as a technique for extraction of the PAHs. Characterization was performed employing gas chromatography and scanning tunneling microscopy. Fifteen of the priority PAHs listed by USEPA (United States Environmental Protection Agency), as well as coronene, were found in the binder samples.

Keywords: chromatography, PAH, recognition, self-assembly, STM

\section{Introduction}

Asphalt binder is one of the products of the distillation of crude oil, which is an extremely complex mixture containing a large number of organic compounds. It has been widely used as a binder for aggregation in road pavement and to manufacture asphalt concrete due to its good adhesion, impermeability and viscoelastic properties. ${ }^{1}$

Unfortunately, fumes released from asphalt binders during road paving, especially in the production of hot mixtures, present a large number of substances that can be hazardous to

*e-mail: 1spinheiro04@yahoo.com.br

In memorian

\# Present address: Universidade Federal do Ceará, Av. Abolição, 3207 Meireles, 60165-081 Fortaleza-CE, Brazil human health. Long time exposure to these fumes can lead to diseases caused by inhalation or skin contact with substances that are carcinogenic and mutagenic, such as the polycyclic aromatic hydrocarbons (PAHs) found in this material. ${ }^{2}$

PAHs are a class of organic elements formed by two to seven benzene rings, whose origin can be natural or anthropogenic. The petroleum industry and the fossil fuel combustion are the main sources of PAH production. ${ }^{2}$

Statistical data reveal that there is evidence of cancer risk, and there is some relation between carcinogenesis and the molecular structure of PAHs. ${ }^{2}$ This implies adequate procedures to detect PAHs in asphalt and the correct use of the material in such a way to avoid environmental and human contamination. ${ }^{3}$ There are few consistent studies devoted to analyze PAHs contents from asphalt binder. 
Therefore, it is of great interest to develop an efficient method that can aid in evaluating the real contribution of the asphalt industry to the PAHs.

This study was performed by employing matrix solid phase dispersion (MSPD) as an analytical method for extraction and analysis of the 16 PAHs classified by USEPA. The performance of MSPD was tested in this work as a method to provide fast and reliable separation of these compounds, which allowed the simultaneous extraction and clean-up of analytes from solid samples. ${ }^{3}$ MSPD has been mainly used for the extraction of organic environmental pollutants in food and biological matrices. ${ }^{3}$ To the best of our knowledge, it is the first time that MSPD was used to isolate PAHs from asphalt binder.

A mixed extract of PAHs obtained from the MSPD was analyzed by gas-chromatography (GC), which was employed to separate and quantify the aromatic compounds. ${ }^{4}$ The extract was later analyzed by Scanning Tunneling Microscopy (STM).

The STM experiments aimed to characterize the size of the components of the asphalt binder extracted by MSPD. It would complement the assignment proposed by the characterization through GC. Gold samples modified with a thiol layer were employed to recognize the PAHs contained in the extract. The thiol employed was 5-(4-pyridinyl)-1,3,4-oxadiazole thiol (HPYT). This molecule forms a stable layer on the gold with a well-known structure, the $\sqrt{ } 3 \times \sqrt{ } 3$ R $30^{\circ}$. 5 This lattice is also observed for the adsorption of other aromatic and alkyl thiols. ${ }^{6,7}$ Thus, a different lattice from the thiol layer would be readily identified in the STM image as due to molecules from the PAH extract. This study is important in molecular sensing since it has potential applications in several fields of chemistry and biochemistry. The analysis by STM and Atomic Force Microscopy (AFM) of the PAHs extracted from the binder are relevant because these techniques have been employed to characterize asphalt binder morphology and its constituents in just a few reports. ${ }^{8}$

\section{Experimental}

\section{Materials}

The asphalt binder penetration grade 50/70 was from the State of Espirito Santo in the Southeast of Brazil, and processed by Lubnor/Petrobrás located in the State of Ceará, northeast of Brazil. Standard PAHs solutions were from Supelco. Internal standard 2-fluoro-biphenyl and the surrogate standards: acenaphthene-d10, phenanthrene-d10, Chrisene-d12 and Perylene-d12 were from Aldrich. The solvents $n$-hexane, toluene, ethyl acetate (P.A. grade) were distilled twice before being employed in the analysis.

\section{Methods}

\section{PAH extraction by MSPD}

Asphalt binder is made of two main constituents, the maltenic and the asphaltene fraction. The maltenic fraction was firstly isolated from the asphaltenes and then it was separated in its constituents, such as aliphatics and aromatics. The PAHs were extracted from a sample of $0.3 \mathrm{~g}$ of asphalt binder (in triplicate) spiked with $20 \mu \mathrm{L}$ of surrogate standards (acenaphthene-d10; phenanthrene-d10, chrysene-d12, and perylene-d12) $10 \mathrm{ppm}$ plus $n$-hexane $(12 \mathrm{~mL})$ and left stirring for 2 hours on a bench stirrer. This procedure is called the "shake" method of separation. The resulting solution was vacuum filtered to remove solid particles left over during the stirring period and then dispersed in $15.0 \mathrm{~g}$ of 60 mesh silica gel. Most of the studies which have employed MSPD applied a 1:4 ratio ( $0.5 \mathrm{~g}$ of sample to $2 \mathrm{~g}$ of solid support). ${ }^{3}$ However, $5 \mathrm{~g}$ of silica was not sufficient for the retention of interferents, $15 \mathrm{~g}$ being the quantity needed for the solid support. After dispersion, the mixture was homogenized and transferred to a column with dimensions $50.0 \mathrm{~cm} \times 1.0 \mathrm{~cm}$ containing $5.0 \mathrm{~g}$ of $\mathrm{Al}_{2} \mathrm{O}_{3}$ and $0.5 \mathrm{~g}$ of copper powder (activated to remove contaminants such as sulfur compounds) both as the cocolumn. The column was rinsed with $50.0 \mathrm{~mL}$ of $n$-hexane to remove and discard the aliphatic compounds present in the asphalt binder. To obtain the PAH fraction, the material remaining into the column was rinsed with three aliquots of $n$-hexane + ethyl acetate in different proportions to optimize the polarity of the elution solvent: ${ }^{9}$ first elution $(36.0 \mathrm{~mL}$ hexane + $4.0 \mathrm{~mL}$ ethyl acetate, second elution $(16.0 \mathrm{~mL}$ $n$-hexane $+4.0 \mathrm{~mL}$ ethyl acetate), third elution $(14.0 \mathrm{~mL}$ $n$-hexane $+6.0 \mathrm{~mL}$ ethyl acetate). The resulting solution was concentrated to $0.5 \mathrm{~mL}$ and $10.0 \mu \mathrm{L}$ of internal standard (2-fluorobiphenyl) $10 \mathrm{ppm}$, was added to the medium. The concentrated aromatic fraction obtained by the MSPD method was then injected in the GC equipment.

\section{$G C$ analysis}

GC was employed to identify the composition of the aromatic fraction of the asphalt binder, relying on their retention times and comparing to those of the standard PAHs. The gas chromatograph was a CG17A-Shimadzu coupled to a flame ionization detector (GC-FID). The separation was performed in a J\&W Scientific DB-5 column (30 m, $0.25 \mathrm{~mm}$ i.d., film thickness $0.25 \mu \mathrm{m}$ ) using split mode (1:20). Hydrogen was employed as the carrier gas at a flow rate of $1.0 \mathrm{~mL} \mathrm{~min} .^{-1}$ Injection temperature: $280{ }^{\circ} \mathrm{C}$ and detector temperature: $300^{\circ} \mathrm{C}$. Calibration curves were built from 0.5 to $100 \mu \mathrm{g} \mathrm{mL}^{-1}$ and the detection limit was

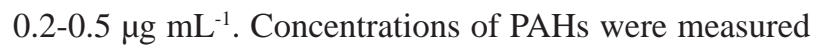
using the response factors related to the internal standard 
(2-fluorobiphenyl) added to the extract prior to injection. A calibration solution was prepared with the PAH standards (16 PAHs), the deuterated PAH solution (surrogate) and the internal standard (2-fluoro-biphenyl). The correlation coefficient $\left(\mathrm{R}^{2}\right)$ varied from 0.9899 to 0.9989 . The PAH confirmation was determined by gas chromatography using the Shimadzu GC 17A instrument coupled to a mass spectrometry detector (Shimadzu model GCMS-QP5000) and the Class 3000 Wiley library was used. The retention times found for each PAH are listed in Table 1.

\section{STM analysis}

5-(4-Pyridinyl)-1,3,4-oxadiazole-2-thiol (HPYT) was prepared in the laboratory following the literature procedure. ${ }^{10}$ Water for preparing molecular solutions was deionized. Gold on mica samples were flame annealed before molecular adsorption. HPYT was adsorbed on gold by dipping the metal sample in 1-2 $\mathrm{mmol} \mathrm{L}^{-1}$ aqueous molecular solutions for 30 minutes, and by rinsing it with water after removal from solution.

The Au-HPYT surface was exposed to the PAHs extracts. A drop of the aromatic extracts in $n$-hexane was added to the surface. The aromatic solution containing the PAHS wet the Au-HPYT surface completely. This indicates compatibility between the hydrophobic SAM and the PAHs solution. The solvent was left evaporating in air for a few minutes followed by STM imaging.
Standard coronene (Aldrich) solutions were made in water:ethanol to minimize molecular solubility and enhance adsorption on the Au-HPYT surface. The aim of this experiment was to compare the molecular structure observed in the STM images obtained for the PAH extracts and that of the standard solution.

The STM was a Nanoscope IIIA equipped with a standard head able to detect tunneling currents from $31 \mathrm{pA}$ to $50 \mathrm{nA}$. Tips were made by clipping $0.25 \mathrm{~mm}$ tungsten wire. STM images were obtained in constant height mode and submitted to a first order flattening tool and low pass filtering. Tunneling was conducted from tip to sample.

\section{Results and Discussion}

\section{MSPD extraction and $G C$ analysis}

Table 1 shows the data obtained for the aromatic fraction extracted by MSPD and also the retention times of the 16 priority PAHs suggested by EPA (Environmental Protection Agency). The retention times of the standard priority PAHs were obtained experimentally and compared with those present in the aromatic sample extracted by MSPD from the binder. Fifteen of the 16 priority PAHs classified by EPA were identified in the asphalt binder sample plus some compounds not formerly taken as standards. This will be further discussed after the STM analysis of the samples.

Table 1. Concentration (ng g $\left.{ }^{-1}\right)$ and retention times ( $\mathrm{min}$ ) of PAHs found in the asphalt binder and those of the priority standards

\begin{tabular}{|c|c|c|c|c|c|}
\hline PAHs & Sample RT ${ }^{\mathrm{a}}$ / min & Concentration / $\left(\mathrm{ng} \mathrm{g}^{-1}\right)$ & Standard deviation & Relative error & Standard PAH RT ${ }^{\mathrm{a}} / \mathrm{min}$ \\
\hline Naphthalene & 14.50 & 3.48 & 0.11 & 3.24 & 14.43 \\
\hline M-Naphthalene & 16.02 & 4.10 & 0.20 & 4.93 & 15.94 \\
\hline Fluorene & 20.59 & 6.76 & 1.56 & 23.07 & 20.56 \\
\hline Phenanthrene & 24.18 & 5.55 & 1.33 & 23.89 & 24.16 \\
\hline Anthracene & 24.44 & 5.90 & 1.34 & 22.65 & 24.38 \\
\hline Fluoranthene & 29.32 & 6.77 & 0.93 & 13.69 & 29.29 \\
\hline Pyrene & 30.23 & 6.01 & 0.93 & 15.43 & 30.23 \\
\hline Benzo(a)anthracene & 35.89 & 6.49 & 1.34 & 20.64 & 35.88 \\
\hline Chrysene & 36.06 & 6.88 & 1.37 & 19.97 & 36.05 \\
\hline Benzo(b) Fluoranthene & 41.69 & 15.78 & 2.64 & 16.69 & 41.65 \\
\hline Benzo(k) Fluoranthene & 41.78 & 9.58 & 1.23 & 12.80 & 41.75 \\
\hline Benzo(a)pyrene & 42.90 & 14.75 & 2.54 & 17.20 & 42.89 \\
\hline Perylene & 43.26 & 11.61 & 3.41 & 29.41 & 43.25 \\
\hline Indene(cd)pyrene & 49.14 & 14.94 & 3.24 & 21.71 & 49.12 \\
\hline Dibenzo(ah)anthracene & 49.28 & 12.56 & 3.07 & 24.47 & 49.28 \\
\hline Benzo(g,h,i)perylene & 49.99 & 16.93 & 2.99 & 17.65 & 49.98 \\
\hline Coronene & 54.10 & 26.58 & 3.02 & 18.05 & 53.58 \\
\hline
\end{tabular}

aretention time. 
The results reveal that the larger PAHs are present in high concentration in the asphalt binder, benzo[g,h,i] perylene having the largest concentration among the 16 priority PAHs. The high concentration of these larger PAHs might contribute to the physical properties of the asphalt binder. It has been discussed that large PAHs with several fused rings can influence the flexibility of the binder. ${ }^{8}$

The validity of the analytical MSPD process for the extraction of the PAH compounds was checked by the recovery of the deuterated standards. The presence and final concentrations of the standards are useful for having a parameter about the yields obtained for the sample after all the analytical process. The final concentrations found for these compounds are seen in Table 2.

Table 2. Retention time (min) and yields of the surrogate standards extracted by MSPD and analyzed by GC

\begin{tabular}{lcc}
\hline Deuterated Standards & $\begin{array}{c}\text { Retention time / } \\
\text { min }\end{array}$ & Yields / (\%) \\
\hline Acenaphthene-d10 (Ace-D) & 18.82 & 55.26 \\
Phenanthrene-d10 (Phen-D) & 24.12 & 51.33 \\
Chrysene-d12 (Chry-D) & 35.95 & 94.60 \\
Perylene-d12 (Per-D) & 43.15 & 83.01 \\
\hline
\end{tabular}

The best yield was found for compounds having 4-6 fused rings. It is noticed that the larger standard PAHs were recovered in the end of the process with a better yield. This could be due to their lower volatility. Low recovery of the smaller compounds is a problem that can occur by the use of these procedures. The smaller compounds having 2-3 fused rings, such as naphthalene, can be volatilized during evaporation of the extracts and the fluxing with nitrogen gas causing a lower recovery rate in the end of the process. ${ }^{9}$

\section{Scanning Tunneling Microscopy}

The extracts containing a mixture of PAHs obtained by $\mathrm{GC}$ were exposed to a flame annealed gold sample. The gold surface was rougher than usual after this procedure. However, no organized domains were observed in the STM images. A modified gold surface was then employed to check if the PAHs would adsorb on this surface. Self-assembled monolayers (SAMs) having different functionalities exposed to the air/solution interface can recognize some chemical groups. ${ }^{6}$ This was thought to work for the PAHs, since 4-octadecylnitrobenzene was employed as a buffer layer for the adsorption of coronene on Highly Oriented Pyrolitic Graphite (HOPG).$^{11}$ In this work, a heteroaromatic thiol was used as the buffer layer. The HPYT molecule is a rigid ligand that has been employed as a surface modifier for the electrochemistry of proteins and in coordination chemistry. ${ }^{5,12}$ The structure of HPYT on the gold surface has been characterized by STM previously. ${ }^{5}$ The molecule forms a slightly distorted $\sqrt{ } 3 \mathrm{x} \sqrt{ } 3 \mathrm{R} 30^{\circ}$ lattice and the molecular structure has some defects such as a few clusters and pits on the surface. ${ }^{5}$

Scanning on the modified surface was performed with a moderate gap impedance to minimize the effects of tip sample interaction. A representative image of the AuHPYT surface is shown in Figure 1. A hexagonal lattice with periodicity of 5.4 x $5.4 \AA \pm 0.4 \AA$ is observed in the image. This structure is stable for a long period, typically months if the sample is left undisturbed and not exposed to the environment. Figure 2 shows a STM image after exposing the Au-HPYT surface to the PAHs solution. A different lattice was observed. The hexagonal HPYT lattice was replaced by parallel rows with a periodicity of $9.0 \AA$. The features inside the rows have also a periodicity of $9.0 \AA$ A The features making up the rows display a six-fold symmetry with a central dip. This structure is pointed by the arrow in Figure 2. The dip in the center of the hexagonal feature is a result of reduction of the tunneling current on this point. The localized density of states (LDOS) of the sample in these areas does not contribute to the tunneling current. Thus, the center of the hexagon appears dark in the image..$^{13}$ The new structure seen in Figure 2 suggests the adsorption of a PAH on the Au-HPYT surface. The tip interacted with the surface during scanning displacing the molecules and thus compromising the imaging.

A few PAHs have been studied by STM, and some of them were imaged on different substrates. ${ }^{14-18}$ The size and shape of the molecular structure found on the Au-HPYT surface, seen in Figure 2, showed similarities to some images of coronene adsorbed on modified HOPG and also to that adsorbed on gold under electrochemical potential. ${ }^{11,14}$ The image of coronene published by Yoshimoto et al. ${ }^{14}$ resembles that obtained in this experimental work. Coronene also appears

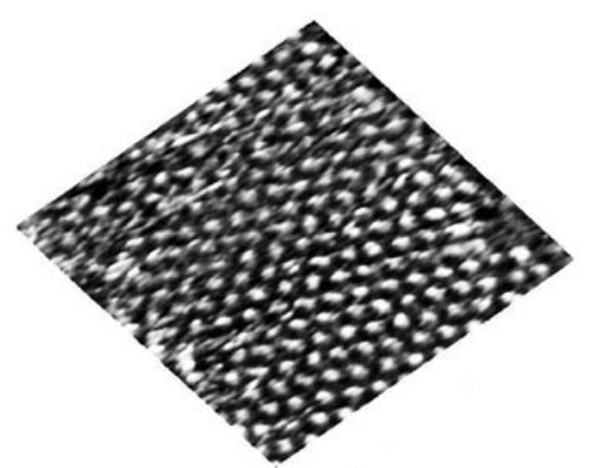

Figure 1. Constant Height (CH) STM image of HPYT on Au(111). Scan area: $80 \times 80 \AA^{2}$. Bias voltage $\left(\mathrm{V}_{\mathrm{s}}\right)$ : $600 \mathrm{mV}$. Tunneling current (I): $200 \mathrm{pA}$. 


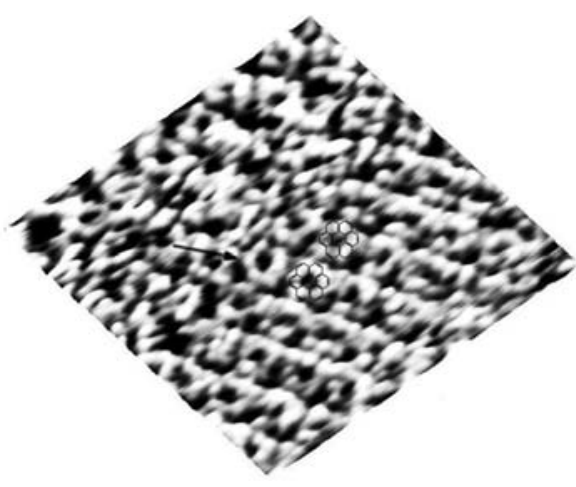

Figure 2. CH STM image of Au-HPYT after exposure to a mixed solution of PAHs. Coronene structure was overlaid arbitrarily on the STM image. Arrow points to a six-fold feature. Area: $71.5 \times 71.5 \AA^{2}$. $\mathrm{V}_{s}: 400 \mathrm{mV}$. I: $500 \mathrm{pA}$.

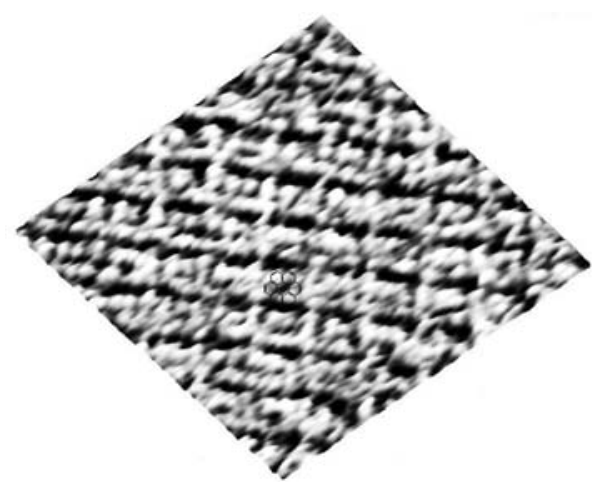

Figure 3. CH STM image of Au-HPYT after exposure to a standard coronene solution. Molecules form periodical rows on the modified surface. Molecular structure was overlaid arbitrarily on the STM image. Area: 70.8 x $70.8 \AA^{2} . \mathrm{V}_{\mathrm{s}}: 50 \mathrm{mV}$. $\mathrm{I}_{\mathrm{t}}: 1.5 \mathrm{nA}$.

as a sixfold object in the image presented by Hietschold et al. ${ }^{19}$ resembling some of the features in Figure 2. The STM image is a mixture of electronic and topographical information and the molecular feature appearing in the image contrast may not be similar to the geometry of the molecule. The STM measures topography and the LDOS. Also, for a molecule adsorbing on a surface, several factors may affect the resulting image. ${ }^{13}$ Comparing the image in figure 2 with the data found in the literature, ${ }^{11,14,19,20}$ the molecule adsorbed on the Au-HPYT surface was assigned to coronene. This way, each hexagonal feature appearing in Figure 2 was assigned to a coronene molecule. The image in Figure 2 shows that the PAH has the molecular ring parallel to the Au modified surface allowing the observation of the molecular internal features.

In order to support this assumption, STM images of standard coronene were made in a similar fashion as that for the aromatic extract. Figure 3 shows the STM image after this procedure. The molecular pattern observed for the standard coronene adsorbed on the Au-HPYT surface is made of rows with a periodicity of $9 \AA$. The features inside the rows also have a periodicity of $9 \AA$. The internal features of the molecules forming the molecular domain are not as clearly defined in the image as those observed for coronene coming from the mixed PAHs solution and displayed in Figure 2. A reason for this behavior is that the tip used to collect the data for the standard coronene sample did not present the same high resolution as that observed for the one sampling the layer grown from the mixed aromatic extract. However, the growth habit made of parallel rows, and the molecular periodicity observed for the standard PAH solution confirm that coronene was adsorbed on the surface when the mixed PAH extract was cast on the Au-HPYT.

EPA does not classify coronene as one of 16 priority PAHs but it can be found in many samples derived from fossil fuels. A recent report using GC to analyze PAHs found coronene with a retention time of $52.02 \mathrm{~min}^{3}$ The peak appearing at $54.10 \mathrm{~min}$ in the asphalt binder chromatogram was assigned to coronene. The differences in retention time found by Sanchez-Brunete et al.,$^{3}$ and in the present study were assigned to the differences in viscosity of the samples. The slurry has a lower viscosity than the asphalt binder and this leads to a lower retention time for a same PAH.

The STM experiments were repeated a few times and the detection of features measuring $c a .9 \AA$ in the STM image were frequent. Smaller features measuring about 5-6 were also observed. However, it appears that the Au-HPYT surface has a higher specificity for coronene. The maltenic fraction of the asphalt binder is richer in coronene as shown by the data of Table 1. When Au-HPYT is exposed to the mixed PAH extract, coronene is preferentially selected by the modified surface. The estimated concentration of coronene in the extract is $26.58 \mathrm{ng} \mathrm{mg}^{-1}$, a value larger than that found for benzo[g,h,i]perylene that was assigned a concentration of $16.93 \mathrm{ng} \mathrm{mg}^{-1}$. Thus, it is found that the asphalt binder is rich in coronene, a large PAH that can impart rigidity to the material.

The STM experiment shows that chemical sensing occurs between the Au-HPYT surface and coronene. The intermolecular forces acting on this system are assigned to hydrophobic interactions. As mentioned earlier, the mixed extract of PAHs wets the modified Au surface. HPYT is hydrophobic and has very low solubility in water, as shown by the fact that an aqueous $1 \mathrm{mmol} \mathrm{L}^{-1}$ molecular solution is already saturated. The HPYT low solubility can be explained by its molecular structure made of heteroaromatic moieties. Hydrophobic forces were proposed as being responsible for chemical sensing between PAHs and an Au-propanethiol modified surface analyzed with Raman spectroscopy. ${ }^{21}$ In addition to the hydrophobic forces, the 
interaction between the Au-HPYT and coronene should take the contribution of electronic nature into consideration. The pyridine moiety in the HPYT molecule has a lone electron pair pointing to solution. The structure of HPYT is shown in Figure 4. Most thiols bind to the gold surface through the sulfur atom. ${ }^{6,7}$ As HPYT presents the same molecular structure observed for the majority of the thiols molecules, it is assumed that the binding of HPYT to gold, is also done through the sulfur atom. Each bright feature in Figure 1 would be mainly due to the LDOS of the sulfur atom. ${ }^{6,7}$ However, the contribution of the aromatic moiety to the STM contrast cannot be discarded. This way, the nitrogen lone pair of the pyridine moiety is available for donation and can be transferred to an empty orbital of the PAH of appropriate energy.

Other surfaces modifiers, such as iodide on $\mathrm{Au}(111)$, which is known to recognizing porphyrins were also tested. ${ }^{22}$ The Au-I surface was exposed to the mixed solution of PAHs, but the STM images for this modified surface did not reveal organized domains that could be assigned to PAHs. Pyridinethiol (PyS) also has a pyridine moiety pointing to solution when adsorbed on Au(111) as HPYT. However, PyS has a shorter molecular chain compared to HPYT, ${ }^{23}$ so it would not contribute to increase the gap between the tip and the modified gold surface too much. The smaller size would help to minimize tip-sample interactions that can lead to overlayer destruction. The attempts to adsorb PAHs on the Au modified by PyS were not successful although this molecule was employed to recognize phthalocyanins. ${ }^{23}$ In order to minimize tip-sample interactions on adsorbed layers, tunneling resistances in the range of $100-600 \mathrm{G} \Omega$ should be employed. ${ }^{24}$ To reach

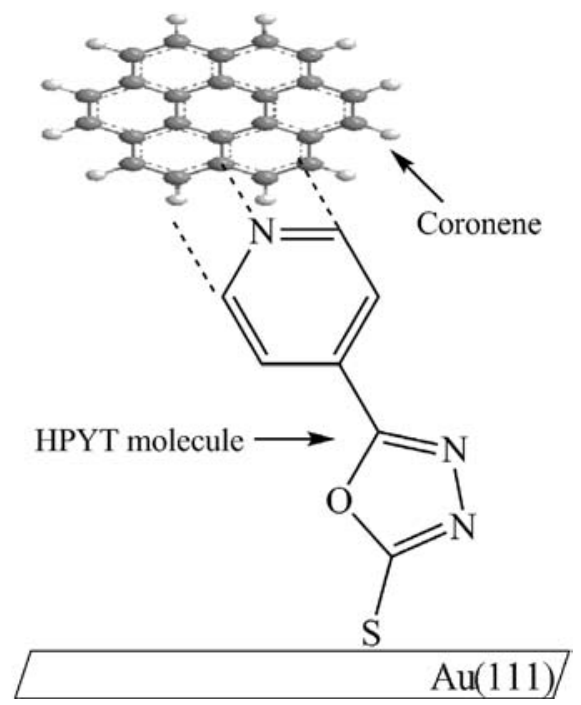

Figure 4. Scheme representing the proposed interaction between the modified surface Au-HPYT and coronene. Broken lines represent weak molecular interaction, such as hydrophobic forces. Drawing is not to scale. these high resistances, it is necessary to use high voltages or very small tunneling currents, in the range of 1-10 pA. The STM employed to image the Au-HPYT sensing the molecules contained in the PAH extract cannot reach this range of tunneling currents. Imaging to acquire the images of Figures 1-3 was done with tunneling resistance in the range $33.3 \mathrm{M} \Omega$ to $3 \mathrm{G} \Omega$.

A scheme of the interaction between the modified Au-HPYT and PAHs is shown in Figure 4. Coronene is supposed to adsorb with the molecular plane almost parallel to the gold surface. This orientation allowed the sampling by the STM of its hexagonal shape as seen in the image of Figure 2.

\section{Conclusions}

The MSPD method shows good performance to extract PAHs from asphalt binder, and it has some advantages over other methodologies. It can be employed to different types of asphalt binder. The method does not require a pre-treatment of the sample, thus preventing losses. The technique avoids the use of large molecules that could deteriorate the GC column. ${ }^{4}$ Most of the PAHs extracted were detected in the sample analyzed by GC chromatogram. However, the method has to be improved for the smaller PAHs since the recovery of the deuterated standards for PAHs having 2-3 rings was very low. The larger PAHs showed a good response to the method, and this reflects in the larger concentration found in the GC analysis.

The STM is a promising technique to study PAHs since it provides information on molecular ordering on surfaces in real time. The STM also shows the size of the molecular constituents helping to estimate the PAH present in a mixture. The use of the modified Au surface highlights that molecular recognition is a key tool to select the desired molecule from a mixture. The HPYT molecule was found to be very selective for coronene. Experimental work is under way to characterize the interaction of this host-guest pair. There is also interest to find molecular species able to recognize the other PAHs found in the asphalt binder. This property would enable the design of specific host-guest pairs to select PAHs from different samples.

\section{Acknowledgments}

We thank CNPq/Funcap for providing financial support through a DCR grant to LSP; CAPES for a grant to PRNF; LEM at IQ-USP for donating Au samples and some chemicals to the development of the work. HPYT was kindly donated by Dr. I.C.N. Diógenes. The asphalt binder was donated by CENPES. 


\section{References}

1. Krisnan, J. M.; Rajagopal, K. R.; Mech. Mater. 2005, 37, 1085.

2. Binet, S.; Pfohl-Leszkowicz, A.; Brandt, H.; Lafonteine, M.; Castegnaro, M.; Sci. Total Environ. 2002, 300, 37; Netto, A. D. P.; Moreira, J. C.; Dias, A. E. X. O.; Barek, J.; Arbilla, G.; Oliveira, A. S.; Ferreira, L. F. V.; Quim. Nova 2000, 23, 765; Campo, L.; Addario, L.; Buratti, M.; Sciebeta, L.; Longhi, O.; Valla, C.; Cirla, P. E.; Martinotti, I.; Foá, V.; Fustinoni, S.; Toxicol. Lett. 2006, 162, 132.

3. Barker, S. A.; J. Biochem. Biophys. Methods 2007, 70, 151; Barker, S. A.; Long, A. R.; Short, C. R.; J. Chromatogr., A 1989, 475, 353; Barker, S. A.; J. Chromatogr., A 2000, 885, 115; Sánchez-Brunete, C.; Miguel, E.; Tadeo, J. L.; J. Chromatogr., A 2007, 1148, 219; Dórea, H. S.; Lopes, W. G.; Quim. Nova 2004, 27, 892; Dórea, H. S.; Sobrinho, L. L.; J. Braz. Chem. Soc. 2004, 15, 690 .

4. Tang, B.; Isacsson, U.; J. Chromatogr., A 2005, 1069, 235.

5. Paulo, T. F.; Silva, M. A. S.; Pinheiro, S. O.; Meyer, E.; Moreira, I. S.; Pinheiro, L. S.; Freire, J. A.; Tanaka, A. A.; de Lima Neto, P.; Moreira, I. S.; Diógenes, I. C. N.; J. Braz. Chem. Soc. 2008, 19, 711 .

6. Love, J. C.; Estroff, L. A.; Kriebel, J. K.; Nuzzo R. G.; Whitesides, G. M.; Chem. Rev. 2005, 105, 1103.

7. Vericat, G.; Vela, M. E.; Benitez, G. A.; Gago, J. A. M.; Torrelles, X.; Salvarezza, R. C.; J. Phys.: Condens. Matter 2006, 18, R867; Duan, L.; Garrett, S. J.; J. Phys. Chem. B 2001, 105, 9812.

8. Mason, J-F.; Leblond, V.; Margeson, J.; J. Microscopy 2006, 221, 17; Watson, B. A.; Barteau, M. A.; Ind. Eng. Chem. Res. 1994, 33, 2358; Loeber, L.; Alexandre, S.; Muller, G.; Triquigneaux, J. C.; Jolivet, Y.; Malot, M.; J. Microscopy-Oxford 2000, 198, 10.

9. Schwab, A. P.; Su, J.; Wetzel, S.; Pekarek, S.; Banks, M. K.; Environ. Sci. Technol. 1999, 33, 1940; Silva, A. A. R.; Lobo, I.; Guedes, C. L. B.; Pinto, J. P.; Semina: Ciências Exatas e Tecnológicas 2006, 27, 105.
10. Henryk, F.; Anna, C.-J.; Waleria, R.; Henryk, T.; Phosphorus, Sulfur Silicon Relat. Elem. 2000, 164, 67.

11. Yang, Y.; Deng, K.; Zeng Q.; Wang, C.; Surf. Interface Anal. 2006, 38, 1039.

12. Du, M.; Zhang, Z-H.; Zhao, X-J.; Xu, Q.; Inorg. Chem. 2006, 45, 5785; Wang Y-T.; Tang, G-M.; Inorg. Chem. Commun. 2007, 10,53 .

13. Sautet, P.; Chem. Rev. 1997, 97, 1097.

14. Yoshimoto, S.; Narita, R.; Wakisaki, M.; Itaya, K.; J. Electroanal. Chem. 2002, 532, 331.

15. Söhnchen, S.; Häkel, K.; Birkner, A.; Witte, G.; Wöll, C.; Chem. Mater. 2005, 17, 5297.

16. Pinheiro, L. S.; Temperini, M. L. A.; Curr. Appl. Phys. 2002 , 2,145 .

17. Florio, G. M.; Werblowsky, T. L.; Muller, T.; Berne, B. J.; Flynn, G. W.; J. Phys. Chem. B 2005, 109, 4520.

18. Gao, L.; Deng, Z. T.; Ji, W.; Lin, X.; Cheng, Z. H.; He, X. B.; Shi, D. X.; Gao, H.-J.; Phys. Rev. B: Condens. Matter Mater. Phys. 2006, 73, 075424 .

19. Hietschold, M.; Lackinger, M.; Griessl, S.; Heckl, W. M.; Gopakumar T. G.; Flynn, G. W.; Microelectron. Eng. 2005, 82, 207.

20. English, W.A.; Hipps, K.W.; J. Phys. Chem. C 2008, 112, 2026.

21. Costa, J. C.; Sant'Ana, A. C.; Corio, P.; Temperini, M. L. A.; Talanta 2006, 70, 1011.

22. Kunitake, M.; Batina, N.; Itaya, K.; Langmuir 1995, 11, 2337.

23. Zhang, Z.; Hou, S.; Zhu, Z.; Liu, Z.; Langmuir 2000, 16, 537.

24. Schönenberger, C.; Sondag-Huethorst, J. A. M.; Jorritsma, J.; Fokkink, L. G. J.; Langmuir 1994, 10, 611.

Received: May 29, 2008

Web Release Date: December 4, 2008 